\title{
Ocorrência de anticorpos antivírus da leucose enzoótica bovina em animais da região médio-norte mato-grossense, Brasil
}

\author{
Enzootic bovine leukosis antibodies in cattle from mid-northern Mato Grosso \\ State, Brazil
}

\author{
Maycon Junior Heidman ${ }^{1}$, Viviane Labs Fischer ${ }^{1}$, Bruno Gomes de Castro ${ }^{2 *}$
}

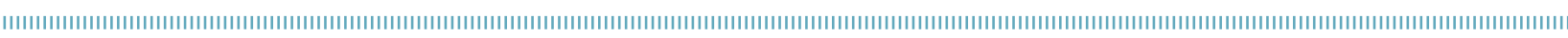

RESUMO: A leucose enzoótica bovina (LEB) é uma enfermidade causada por um retrovírus e pode apresentar um quadro de linfocitose persistente ou linfossarcomas em bovinos adultos. Este estudo teve como objetivo realizar um levantamento sorológico, por meio do teste de imunodifusão em gel agar (IDGA), de bovinos de corte e de leite, bem como de animais puros de origem (POs), criados nos municípios de Sinop e Sorriso, a fim de se conhecer a distribuição e a ocorrência de anticorpos antivírus da LEB na referida região. De acordo com os resultados obtidos, foi verificado que a prevalência acumulada nas três categorias foi de 11,78\% de soropositivos, sendo $12,19 \%$ para bovinos de corte, $11,20 \%$ para o rebanho leiteiro e 9,09\% em animais POs. Dessa forma, este estudo demonstrou que a LEB se faz presente no estado de Mato Grosso, sendo possível verificar que a LEB apresenta índices de prevalência abaixo dos encontrados em outras regióes do país.

PALAVRAS-CHAVE: epidemiologia; sanidade animal; retrovírus bovino; Mato Grosso.
ABSTRACT: The enzootic bovine leukosis (EBL) is a disease caused by a retrovirus and can be presented as a persistent lymphocytosis, or bovine lymphosarcomas in adult cattle. This study aimed to conduct a serological survey of beef cattle, dairy herd and in purebred cattle raised in the cities of Sinop and Sorriso, in order to understand the distribution and occurrence of antibodies anti-EBL virus in that region. According to the results obtained, the prevalence in the three categories was $11.78 \%$ of serum positives, where $12.19 \%$ for beef cattle, $11.02 \%$ for the dairy herd and $9.09 \%$ in purebred cattle animals. Thus, this study demonstrated that EBL is present in Mato Grosso State, and EBL's prevalence rates lower than others reported in several regions of the country.

KEYWORDS: epidemiology; animal health; bovine retrovirus; Mato Grosso State. 
A leucose enzoótica bovina (LEB) é uma doença infectocontagiosa com evolução crônica que pode levar à manifestação de uma linfocitose persistente e linfossarcomas em bovinos. $\mathrm{O}$ vírus causador da enfermidade é um oncovírus tipo $\mathrm{C}$ da família Retroviridae, gênero Deltaretrovirus, com material genético composto por duas fitas simples de RNA (FLORES, 2007).

Com relação aos aspectos epidemiológicos, de acordo com a literatura, existem dois tipos de transmissão do vírus denominados vertical e horizontal. A forma mais importante de transmissão é a horizontal, pois pode ocorrer através do contato do animal sadio com os fluidos biológicos do animal contaminado, porém a leucose bovina não é transmitida com tanta facilidade como outras doenças infecciosas de bovinos, requer um íntimo e prolongado contato entre os animais. Outra forma de transmissão horizontal é a iatrogênica, caracterizada pela transmissão do vírus pelo sangue através de equipamentos contaminados que foram reutilizados (HüBNER et al., 1997).

Atualmente, a LEB está amplamente difundida em todo o território brasileiro, porém os trabalhos apresentam variação de taxas de prevalência. Na regiáo Sul, Sponchiado (2008) verificou soropositividade de 49,04\% do rebanho leiteiro analisado. Em Minas Gerais, RAJÁo (2008), utilizando também gado leiteiro como unidade amostral, verificou uma prevalência de 79,7\%. Na Bahia, Távora; Birgel (1991) detectaram que $16,1 \%$ dos bovinos avaliados apresentavam anticorpos antivírus da LEB. Já no estudo de Fernandes et al. (2009) foi observada uma taxa de prevalência de 37\% no rebanho de vacas leiteiras estudado de Tocantins, podendo demonstrar, dessa forma, que a LEB está presente em rebanhos da região Norte.

O diagnóstico tem papel fundamental no controle e na erradicação da LEB, visto que ela não apresenta nenhuma forma de tratamento efetiva. O exame físico é uma ferramenta importante no diagnóstico da doença no animal, porém só é efetivo em casos em que o animal apresenta formaçôes tumorais (Troiano, 2009). Nos casos assintomáticos, métodos indiretos devem ser utilizados, sendo recomendada pela Organização Mundial de Saúde Animal (OIE) a técnica de imunodifusão em gel de ágar (IDGA) (OIE, 2008). Porém, outras técnicas também podem ser utilizadas, tais como fixação de complemento, soroneutralização, ELISA e técnicas moleculares, como a reação em cadeia da polimerase (PCR) (Troiano, 2009).

Diante da dificuldade no diagnóstico, no tratamento, no controle e na profilaxia, este estudo teve como objetivo realizar um levantamento, pela técnica de IDGA, da ocorrência de anticorpos antivírus da LEB em rebanhos de bovinos de corte e de leite de municípios da região médio-norte mato-grossense, a fim de se verificar o status sanitário dessa região.

Foram coletadas 280 amostras de sangue de bovinos, machos e fêmeas, de corte e de leite, em idade reprodutiva, entre os meses de novembro de 2011 e abril de $2012 \mathrm{em}$ 10 propriedades rurais localizadas nos municípios de Sinop e Sorriso, tendo como base uma populaçáo de aproximadamente 170 mil cabeças, de acordo com o Anuário Estatístico de Mato Grosso, bem como prevalência esperada de 20\%, nível de confiança de $95 \%$ e erro absoluto de $5 \%$ utilizando o programa Epi info, versão 7.0 (CDC, 2012).

A IDGA foi a técnica utilizada como prova de triagem, conforme recomendado por Pinheiro JR. et al. (2013), e realizada no Laboratório de Doenças Infecciosas do Hospital Veterinário da Universidade Federal de Mato Grosso (UFMT), Sinop. Foram utilizados kits produzidos pelo Instituto de Tecnologia do Paraná (TECPAR), sendo a técnica realizada de acordo com as instruçóes do fabricante.

Utilizou-se Agar Noble (MERCK) 0,9\% em solução tampão com pH 7,3 e solução de cloreto de sódio a 8,5\% Após a solidificação, o gel foi perfurado com roseta metálica, obtendo-se 3 conjuntos hexagonais de orifícios de 4,0 $\mathrm{mm}$ por placa, cada conjunto tem 7 orifícios. Foi feita a distribuição de $20 \mu \mathrm{L}$ de soro/antígeno, sendo as placas mantidas em atmosfera seca, com a leitura realizada $48-72$ h após, com luz indireta sobre fundo escuro, sendo considerada definitiva a última leitura.

A caracterização da significância entre as diferenças observadas nas frequências de animais reativos segundo o gênero, $o$ perfil zootécnico de criaçáo e a procedência foram determinadas por meio do teste de ANOVA (ZAR, 1999), pelo programa Biostat 5.0. O nível de significância adotado foi de 5\%.

De acordo com os resultados dos testes de IDGA realizados, foram verificados que 33 animais, dos 280 avaliados, apresentavam anticorpos antivírus da LEB, representando 11,78\% de soropositividade no rebanho dos municípios de Sinop e Sorriso.

A prevalência observada neste estudo se mostrou abaixo da encontrada por diversos estudos realizados no Brasil. Na regiáo Sul, estudos recentes no Paraná relatam taxas de prevalência de 40,7, 55,56 e 49,04\% nos levantamentos de Leuzzi Jr. et al. (2003), Meirelles et al. (2009) e Sponchiado (2008), respectivamente, no rebanho leiteiro estudado do referido Estado.

De acordo com Carvalho et al. (1996), a LEB é uma enfermidade muito importante na bovinocultura leiteira, seja em decorrência de uma maior idade dos animais, seja pelo íntimo contato devido ao sistema de criaçáo utilizado. Em seu estudo, os autores verificaram que os rebanhos leiteiros avaliados apresentaram $18,4 \%$ de soropositividade para LEB $(n=374)$, enquanto em animais da raça Nelore não houve detecção de nenhum animal soropositivo.

Em condiçôes ecológicas semelhantes as observadas no estado de Mato Grosso, Andrade; Almeida (1991) realizaram o único estudo registrado até o presente momento na regiáo Centro-Oeste. De acordo com os autores, quando avaliada a prevalência em relação à raça do animal, foi verificado que o rebanho holandês apresentou a maior frequência (46\%), seguido por animais mestiços (39,2\%), Gir (37,9\%) e Nelore $(13,2 \%)$. De acordo com os resultados obtidos, esses autores 
relataram que as condiçóes de manejo e criação dos animais sáo preponderantes no que se refere à ocorrência da LEB. Porém, os pesquisadores comentaram que animais de corte criados extensivamente também apresentam predisposição ao agente, mas que muitas das vezes não desenvolvem a fase clínica da doença por conta da cronicidade dos sintomas clínicos.

No presente estudo, quando avaliada a ocorrência de anticorpos antivírus da LEB, foi verificada diferença significativa $(\mathrm{p} \leq 0,05)$ entre as prevalências acumuladas dos rebanhos de corte e de leite e do rebanho de animais puros de origem (POs) nos municípios de Sorriso e Sinop (Tabela 1).

Este resultado demonstra que o vírus está circulando na região estudada, apesar de não ter sido verificado nenhum animal com sintomatologia clínica, reforçando a hipótese de que essa enfermidade muitas vezes se apresenta de forma assintomática, ou, devido à sua cronicidade, a sintomatologia tarda a ser observada.

Quando comparada a distribuição entre os rebanhos de leite e corte nos municípios estudados, foi possível verificar diferença significativa ( $p \geq 0,05)$ entre eles (Tabela 2$)$. Isso pode ser explicado pela idade dos animais, bem como pelo seu tipo de criação. No caso do rebanho de corte, em Sinop a prevalência observada apresentou-se menor que em Sorriso. Isso possivelmente ocorreu porque em Sinop (2,5\%) foram realizadas coletas de animais criados em sistema extensivo, enquanto em Sorriso os animais analisados estavam em propriedades com sistema de semiconfinamento, o que aumenta o contato

Tabela 1. Distribuição da prevalência de leucose enzoótica bovina entre os perfis zootécnicos de animais da região médionorte mato-grossense, Brasil, 2012.

\begin{tabular}{lccc} 
Perfil zootécnico & Negativos & Positivos & Prevalência \\
\hline Gado de corte & 144 & 20 & $12,19 \%^{\mathrm{a}}$ \\
\hline Gado de leite & 103 & 13 & $11,20 \%^{\mathrm{a}}$ \\
\hline $\begin{array}{l}\text { Gado Nelore } \\
\text { puro de origem }\end{array}$ & 30 & 3 & $9,09 \%^{\mathrm{b}}$ \\
\hline
\end{tabular}

$p<0,05$; Letras iguais em uma mesma coluna significam que não houve diferença estatística. Letras diferentes significam que ocorreram diferenças significativas ao nível de 95\% de confiabilidade.

Tabela 2. Distribuição da prevalência de leucose enzoótica bovina entre os perfis zootécnicos e município de origem de animais da região médio-norte mato-grossense, Brasil, 2012.

\begin{tabular}{lc} 
Perfil/município & Prevalência \\
Gado de leite - Sinop & $18,42 \%^{\mathrm{a}}$ \\
\hline Gado de leite - Sorriso & $6,66 \%^{\mathrm{b}}$ \\
\hline Gado de corte - Sinop & $2,50 \%^{\mathrm{c}}$ \\
\hline Gado de corte - Sorriso & $15,32 \%^{\mathrm{d}}$ \\
\hline
\end{tabular}

$\mathrm{p} \leq 0,05$; Letras iguais em uma mesma coluna significam que não houve diferença estatística. Letras diferentes significam que ocorreram diferenças significativas ao nível de 95\% de confiabilidade. entre os indivíduos, favorecendo a disseminação do agente, sendo demonstrado pela prevalência de $15,32 \%$ observada.

Outros estudos apresentaram resultado similar. BIRgEL et al. (1994) verificaram, no estado de São Paulo, 4,2\% de bovinos de corte da raça Nelore sororreagentes criados extensivamente, enquanto, em outro estudo, Modena et al. (1984) observaram soropositividade em 15,4\% em rebanhos de corte em Minas Gerais, apesar de não citarem o tipo de criação realizada.

De forma semelhante, quando comparada a prevalência da LEB nos rebanhos leiteiros de Sinop e Sorriso, foi observada diferença estatística entre eles (Tabela 3). Apesar de serem rebanhos caracterizados por raças distintas, visto que as propriedades visitadas de Sinop apresentavam vacas da raça Jersey (18,42\%), e as de Sorriso, animais predominantemente da raça Holandesa ou Mestiça Holandesa (6,66\%), os sistemas de criação dos animais eram semelhantes, bem como a faixa etária dos indivíduos analisados. Sendo assim, outro fator pode ter sido fundamental para a diferença observada entre os municípios.

Mesmo assim, o resultado acumulado observado neste estudo demonstra que os rebanhos leiteiros dos municípios estudados $(11,20 \%)$ apresentam baixas efetivamente menores que estudos realizados em outros Estados brasileiros (MEgID et al., 2003; Polleto et al., 2004; Fernandes et al., 2009). Esse fato possivelmente se deve à diferença ecológica entre as regióes estudadas. Nos municípios estudados, a temperatura média anual é de $29,3^{\circ} \mathrm{C}$ (SEPLAN, 2010), fato que provavelmente diminui a resistência do vírus no ambiente, bem como força os animais a diminuírem a aglomeração, reduzindo a morbidade do agente, quando comparado com outras situaçóes de clima, principalmente de estados que apresentaram altas taxas de prevalência. Concordando com o discutido acima, não foi observada diferença significativa entre as prevalências acumuladas entre os rebanhos de Sinop e Sorriso (Tabela 3).

Sendo assim, este estudo demonstrou que a LEB se faz presente no estado de Mato Grosso, com diferença significativa entre os animais criados em sistemas semi-intensivos e os criados extensivamente.

Dessa forma, novos estudos devem ser realizados a fim de se conhecer a ocorrência e a distribuição dessa enfermidade em todo o território mato-grossense, para que políticas públicas possam efetuar de modo mais dinâmico o controle e a prevenção da LEB dentro do estado de Mato Grosso.

Tabela 3. Distribuição da prevalência de leucose enzoótica bovina entre os municípios de origem de animais da região médio-norte mato-grossense, Brasil, 2012.

\begin{tabular}{lc} 
Município de origem & Prevalência \\
Sorriso & $12,37 \%^{\mathrm{a}}$ \\
\hline Sinop & $10,25 \%^{\mathrm{a}}$ \\
\hline
\end{tabular}

p > 0,05; Letras iguais em uma mesma coluna significam que não houve diferença estatística. Letras diferentes significam que ocorreram diferenças significativas ao nível de 95\% de confiabilidade. 
ANDRADE, J.R.A.; ALMEIDA, M.M.R. Prevalência da Leucose Enzoótica Bovina na Bacia Leiteira de Goiânia, Goiás. A Hora Veterinária, v.10, n.60, p.49-53, 1991.

BIRGEL, E.H.; BENESI, F.J.; D’ANGELINO, J.L.; AYRES, M.C.C.; COSTA, J.N.; CARNEIRO, P.A.M.; ARAUJO, W.P.; BIRGEL, E.H.; SOUZA, K.W. Prevalência da Infecção pelo Vírus da Leucose dos Bovinos em rebanhos leiteiros criados no Estado do Amazonas, Brasil. Acta-Amazonica, v.33, n.1, p.111-125, 2003.

CARVALHO, L.; BENESI, F.J.; BIRGEL JUNIOR, E.H.; BIRGEL, E.H. Prevalência de anticorpos séricos de anti-vírus da Leucose dos bovinos em animais da raça Holandesa preto e branca e zebuínos da nelore, criados no Pólo Regional de Londrina, estado do Paraná. Semina: Ciências Agrárias, v.17, n. 1, p.53-57, 1996.

FERNANDES, C.H.C.; DE MELO, L.E.H.; DA S. TENÓRIO T.G.; MENDES, E.I.; DE C. FERNANDES; A.C.; RAMALHO, T.R.R.; MOURA SOBRINHO, P.A.; MOTA R.A. Soroprevalência e fatores de risco da infecção pelo vírus da leucose dos bovinos em rebanhos leiteiros da região norte do estado do Tocantins, Brasil. Arquivos do Instituto Biológico, v.76, n.3, p.327-334, 2009.

FLORES, E.F. Virologia Veterinária. $1^{\text {a }}$ ed. Santa Maria: Editora da UFSM, 2007. 888p.

HÜBNER, S.O.; WEIBLEN, R.; MORAES, M.P.; SILVA, A.M.; CARDOSO, M.J.L.; PEREIRA, N.M.; ZANINI, M. Infecção intra-uterina pelo vírus da leucose bovina. Revista Brasileira de Reprodução Animal, v.21, n.4, p.8-11, 1997.

LEUZZI JUNIOR, L.A.; GUIMARÃES JUNIOR, J.S.; FREIRE, R.L.; ALFIERI, A.F.; ALFIERI, A.A. Influência da idade e do tamanho do rebanho na soroprevalência da Leucose Enzoótica Bovina em rebanhos produtores de leite tipo $B$, na região de Londrina do estado do Paraná. Revista Brasileira de Ciências Veterinária, v.10, n.2, p.93-98, 2003.

MEGID, J.; NOZAKI, C.N.; KURODA, R.B.S.; CRUZ, T.F.; LIMA, K.C. Ocorrência de Leucose Enzoótica Bovina na Microrregião da Serra de Botucatu. Arquivo Brasileiro de Medicina Veterinária e Zootecnia, v.55, n.5, p.645-646, 2003.

MEIRELLES, C.; DITTRICH, T.; CIPRIANO, F.; OLLHOFFR, D. Evolução da soroprevalência da Leucose Enzoótica Bovina em um rebanho bovino leiteiro universitário. Ciências Agrárias, v.30, n.3, p.671-678, 2009.
MODENA, C.M.; GOUVEIA, A.M.G.; AZEVEDO, N.A.; SILVA, J.A.; VIANA, F.C.; REHFELD, O.A.M. Leucose Enzoótica Bovina: I prevalência em rebanhos de alta linhagem no Estado de Minas Gerais. Arquivo Brasileiro de Medicina Veterinária e Zootecnia, v.36, n. 1, p.39-45, 1984.

OFFICE INTERNACIONAL DES EPIZOOTIES (OIE). Enzootic Bovine Leukosis. Chapter 2.4.11. OIE Terrestrial Manual, 2008. p.729-738.

PINHERIO JUNIOR, J.W.; SOUZA, M.E.; PORTO, W.J.N.; LIRA, N.S.C.; MOTA, R.A. epidemiologia da infecção pelo vírus da leucose enzoótica bovina (LEB). Ciência Animal Brasileira, v.14, n.2, p.258-264, 2013.

POLLETO, R.; KREUTZ, L.C.; GONZALES, J.C.; BARCELLOS, L.J.G. Prevalência de tuberculose, brucelose e infecções víricas em bovinos leiteiros do município de Passo Fundo, RS. Ciência Rural, v.34, n.2, p.595-598, 2004.

RAJÃO, D.S. Efeito da infecção pelo vírus da leucose enzoótica bovina na produção de leite e reprodução de rebanhos leiteiros. 2008. 26p. Dissertação (Mestrado) - Universidade Federal de Minas Gerais, Escola de Veterinária, 2008.

SEPLAN, Secretaria de Planejamento do Estado de Mato Grosso. Anuário Estatístico do Estado de Mato Grosso 2010. Disponível em: <www.seplan.mt.gov.br>. Acessado em: 18 jan. 2012.

SPONCHIADO, D. Prevalência de anticorpos séricos anti-Vírus da Leucose Enzoótica Bovina em rebanhos da raça Holandesa Preta e Branca, criados no Estado do Paraná. 2008. 101 f. Dissertação (Mestrado em Ciências Veterinárias) - Setor de Ciências Agrárias, Universidade Federal do Paraná, Curitiba, 2008.

TÁVORA, J.P.F.; BIRGEL, E.H. Prevalência da infecção pelo vírus da leucose bovina em rebanhos leiteiros criados na região de Pólo Itabuna, Estado da Bahia. Arquivo da Escola de Medicina Veterinária da Universidade Federal da Bahia, v.14, n.1, p.164-183, 1991.

TROIANO, L.D.C. Produção e caracterização de anticorpos monoclonais anti-gp51 do vírus da Leucose Bovina (VLB). 2009. Dissertação (Mestrado em Ciências Veterinárias) - Setor de Ciências Agrárias, Universidade Federal do Paraná, Curitiba, 2009.

ZAR, J.H. Biostatistical analysis. $4^{\text {th }}$ ed. Upper Saddle River: Prentice Hall, 1999. 663p. 